\title{
Mental health in Uzbekistan
}

\author{
Dina Gazizova MBBS MRCPsych, ${ }^{1}$ Abdulla Mazgutov PhD MBBS, ${ }^{2}$ \\ Grigoriy Kharabara MBBS $^{3}$ and Elena Tsoyi MBBS ${ }^{4}$
}

${ }^{1}$ Central and North West London NHS Foundation Trust, email dina.gazizova@nhs.net; ${ }^{2}$ West London Mental Health NHS Trust ${ }^{3}$ Deputy Chief Doctor, Clinical Psychiatric Hospital of the Ministry of Health, Uzbekistan ${ }^{4} \mathrm{NPO}$ on Non-Communicable Diseases and Environment, WHO office in Uzbekistan

U zbekistan is a landlocked central Asian country with an area of $447400 \mathrm{~km}^{2}$. It borders Kazakhstan in the north, Kyrgyzstan and Tajikistan in the east, Turkmenistan in the west and Afghanistan in the south. Uzbekistan has 14 regions (provinces). In 1991 it emerged as a sovereign country after more than a century of Russian rule - first as part of the Russian empire and then as a component of the Soviet Union.

The population is 27767100 , which represents half the region's total population. A third of the population is younger than 14 , and just $4.7 \%$ are over $65 ; 64 \%$ of the population is rural. Uzbeks comprise a majority (80\%) of the total population. Other ethnic groups include Russians, Koreans, Tajiks, Kazakhs, Karakalpaks and Tatars. The largest religious group are Muslims (Central Intelligence Agency, 2010). The literacy rate is $97 \%$ (United Nations Children's Fund, 2008). The life expectancy at birth is 64.5 years for males and 70.9 for females (United Nations, 2009).

The country is a low-income group country based on World Bank criteria. The health budget represents 3.1\% of the country's gross domestic product. The per capita total expenditure on health is US\$91, and the per capita government expenditure on health is $\$ 68$. Overall, $2.3 \%$ of the government's healthcare expenditure is directed towards mental health (World Health Organization, 2007).

\section{Mental health policy and legislation}

Psychiatric care in Uzbekistan is provided only by the public sector. Mental health was declared a public health priority area by a presidential decree (no. UP-2107) in November 1998 (World Health Organization, 2007). Benefits for people with mental disorders were defined by a Decree of the Cabinet of Ministers of Uzbekistan in March 1997. In August 2000 the Uzbek parliament adopted comprehensive mental health legislation, under the title 'On Psychiatric Care for the Population'. Later it issued a supplement entitled 'Compulsory Hospitalisation in Psychiatric Establishments', which was aimed at protecting the legal rights and interests of patients with mental illness (Cooper et al, 2008). A national suicide prevention strategy (2010-20) was adopted by the government in December 2009.

Mental health services are regulated by the Department of Mental Health in the Ministry of Health. The department employs a number of specialists, including a chief psychiatrist, a chief child psychiatrist, a chief forensic psychiatrist and a suicide specialist. Also, each region of Uzbekistan has a chief psychiatrist responsible for the mental health services.

Mental health issues and planning are regularly discussed at annual conferences that involve all stakeholders.

All patients with mental disorders have a right to essential psychotropic medicines either free of charge or subject to at least an $80 \%$ subsidy. Additional mental health patient benefits include free nursing care and treatment in psychiatric hospitals, as well as free provision of special drugs for out-patients.

\section{Mental health service delivery}

After independence in 1991, Uzbekistan inherited a centralised and hierarchically organised model of healthcare from the Soviet Union. There was over-provision of hospital beds, which contributed to an imbalance in the overall structure of the healthcare system. On the whole, the Soviet system tended to neglect primary care and placed too much emphasis on specialist and hospital care. During the first years of independence, health policy focused on improving primary care facilities (poly-clinics in cities and rural primary medical practices) and cutting the cost of in-patient facilities (Ahmedov et al, 2007).

With a view of achieving deinstitutionalisation of psychiatric services, the number of psychiatric beds was reduced by a factor of 1.6, to 7831. The funds gained through deinstitutionalisation were supposed to be transferred from hospital to out-patient (and primary care) mental health facilities. Unfortunately, a majority of these funds were transferred from the mental health system to other fields of healthcare.

Out-patient psychiatric care is provided by 22 neuropsychiatric out-patient clinics (dispensaries), 17 of which offer 24-hour care. There are also 3-day treatment clinics in the psychiatric hospitals. There are 446 poly-clinics that offer psychiatric care, including 226 in adult psychiatry, 156 in child psychiatry and 27 in adolescent psychiatry. Ten of the 14 regions of Uzbekistan provide day treatment facilities for persons with mental disorders; these offer a level of service that falls between out-patient and in-patient care and give opportunities for occupational therapy and rehabilitation.

There are 13 psychiatric hospitals with a total of 29.2 beds per 100000 population. All of these establishments are 
Table 1 The number of psychiatrists by subspecialty, 2009

$\begin{array}{lr}\text { Psychiatric subspecialty } & \text { Numbers in } 2009 \\ \text { Adult psychiatrists } & 674 \\ \text { Child psychiatrists } & 170 \\ \text { Adolescent psychiatrists } & 57 \\ \text { Forensic psychiatrists } & 14 \\ \text { Psychotherapists } & 21 \\ \text { Suicidologists } & 1\end{array}$

organisationally integrated with mental health out-patient facilities. Eleven hospitals have emergency psychiatric care teams, which can assess and review at-risk patients at home. Nine per cent of the beds in mental hospitals are reserved for children and adolescents. Furthermore, nine psychiatric hospitals have special adolescent departments (240 beds).

There are, in addition, 12 in-patient drug and alcohol services, with a total number of 325 beds, and 890 beds are for the treatment of people with mental disorders in forensic in-patient units.

There are 3178 primary rural medical practices. General practitioners can provide emergency care to patients with mental disorders and refer them to a psychiatrist. Assessment and treatment guidelines for key mental health conditions in non-physician-based primary care are not available.

The suicide rate in Uzbekistan during 1984-90 was reported to be 11.8 per 100000 (World Health Organization, 2005). This might not reflect the real picture, as misclassifications could occur in cases where there was a wish to conceal a murder. Negative attitudes towards suicide, especially in Muslim regions, where suicide is taboo, might also have contributed to under-reporting of suicide (Wasserman \& Varnik, 1998). From 2005 to 2009, 8286 people attempted suicide. There is a specialist centre for suicide prevention which analyses the suicide rate and supports people with a risk of suicide. Every region has a crisis unit for people who have attempted suicide, located in emergency medicine centres. In addition, regional telephone helpline services have been created and are staffed with trained professionals who give advice and information to anyone in distress. In 2009 the helpline served 10090 people, including 333 with suicidal intentions.

\section{Psychiatric training, subspecialties and allied professionals}

Medical undergraduate training lasts 7 years and is offered by seven medical schools. All seven and the Tashkent Institute of Postgraduate Medical Education also offer postgraduate psychiatric training. In 2009 there were 52 doctors in training: 26 residents and 26 masters. In addition, 184 doctors attended refresher training courses run by the Tashkent Institute of Postgraduate Medical Education.

At the end of 2009 there were 937 psychiatrists working in Uzbekistan. Their distribution by subspecialty is presented in Table 1. In the same year, 2442 psychiatric nurses participated in the treatment of people with mental illness in Uzbekistan. All of them had a general medicine background before entering psychiatry. Whereas the World Health Organization recommends a psychiatric doctor:nurse ratio of
$1: 4$, in Uzbekistan it is $1: 2.9$. The number of healthcare assistants working in psychiatry was 3196 in 2009.

There are no social workers or occupational therapists. Because of a lack of trained professionals, 150 places for clinical psychologists remain vacant and in all mental health facilities there is total of only 23 psychologists.

\section{Research}

Research in Uzbekistan is focused on community epidemiological studies, clinical psychiatry, pharmacological, psychosocial and psychotherapeutic interventions and surgical and electroconvulsive treatment. From 2005 to 2010 there were 234 publications on health from Uzbekistan identified in PubMed, of which 16 (6.8\%) were on mental health.

\section{Obstacles and areas for development}

Despite some positive changes in mental health policy and legislation over the past two decades, insufficient funding has led to a deterioration of mental health services. A reduction in the number of psychiatric beds and day treatment clinics as well as difficulties with drug supply are the main problems. The overall number of mental health professionals is continuing to decline and as a consequence a major treatment gap can be expected for the increasing number of patients who need specialist help. Furthermore, many specialists are approaching retirement age and an annual output from medical training colleges of 52 doctors will not be enough to cover future service needs.

To overcome these problems, it would be desirable, first, to decentralise mental health services and create mental health units within general hospitals. Second, despite initial efforts to integrate mental health services into primary care through the training of general practitioners, there is still a need for better integration and a more comprehensive approach to increasing the accessibility of care for patients with mental health problems at primary care level.

\section{References}

Ahmedov, M., Rechel, B., Alimova, V., et al (2007) Primary health care reform in Uzbekistan. International Journal of Health Planning and Management, 22, 301-318.

Central Intelligence Agency (CIA) (2010) Uzbekistan. In World Factbook. CIA. Available at https://www.cia.gov/library/publications/the-worldfactbook/geos/uz.html (accessed November 2010).

Cooper, J. E., Sartorius, N., Nixon, N., et al (eds) (2008) Images of Mental IIIness in Central Asia: A Casebook with Commentaries. Global Initiative in Psychiatry (GIP). Available from the Royal College of Psychiatrists.

United Nations (2009) Human Development Report: Uzbekistan. UN.

United Nations Children's Fund (2008) Uzbekistan, statistics. UNICEF. Available at http://www.unicef.org/infobycountry/uzbekistan_statistics. html (accessed August 2010).

Wasserman, D. \& Varnik, A. (1998) Reliability of statistics on violent death and suicide in the former USSR, 1970-1990. Acta Psychiatrica Scandinavica, suppl. 394, 34-41.

World Health Organization (2005) Uzbekistan. In Mental Health Atlas. WHO.

World Health Organization (2007) WHO-AIMS Report on Mental Health System in Uzbekistan. WHO and Ministry of Health (Uzbekistan). 